\title{
El cauce mítico dionisiaco presente en los festivales de música electrónica
}

\author{
Citlaly Aguilar Campos ${ }^{1 *}$
}

\begin{abstract}
Resumen de significados que refleja condiciones de nuestra era y de la contracultura.

Abstract conditions of our era and counterculture.

\section{Palabras Clave}

Mito, Festivales de música, Dioniso, Significado, Comunidad.

Keywords

Myth, Music festivals, Dionysus, Meaning, Community.

${ }^{1}$ Doctora en Ciencias Políticas y Sociales por la Universidad Nacional Autónoma de México.

*Autor para correspondencia: citlaestrella@hotmail.com
\end{abstract}

El mito es una parte vital en la existencia del ser humano, permite comprender e interactuar con el entorno, ayuda a formar identidad y comunidad. El texto presentado problematiza sobre la prevalencia de las narrativas míticas, a partir de su rastreo en fenómenos como lo son los festivales de música electrónica. Se utilizará la categoría de cauce mítico de Gilbert Durand para identificar cómo el mito dionisiaco está vigente en eventos como el Electric Daisy Carnival (EDC), Tomorrowland y Burning Man; los cuales han perpetuado este mito al fomentar una atmósfera festiva, extática y de espíritu colectivista que genera un espacio común de intercambio

The myth is a vital part in the existence of the human being, allows us to understand and interact with the environment, helps to form identity and community. The present research problematizes about the prevalence of mythical narratives from their tracking in phenomena such as electronic music festivals. Gilbert Duran d's category called mythical wadi, will be used to identify how the Dionysian myth is present at events such as Electric Daisy Carnival (EDC), Tomorrowland and Burning Man; which have perpetuated this myth by promote a festive, ecstatic and collectivist spirit that generates a common space for the exchange of meanings that reflects

\section{Introducción}

El ser humano es un ente temporal, vive y se entiende a través del tiempo; las narraciones desde la perspectiva del filósofo francés, Paul Ricoeur, son muestra de esta temporalidad ontológica. Los relatos en un principio formaron parte de la tradición oral hasta que la escritura fue siendo parte intrínseca de los grupos sociales. Cabe resaltar que el registro escrito no es una transcripción del lenguaje oral, cada sistema lingüístico guarda sus peculiaridades, por lo que las narrativas orales sufrieron transformaciones inevitables al pasar por tal transformación.
Una de las herramientas que permitieron a los seres humanos la comprensión de su entorno fue el mito, considerado por Ernest Cassirer (2009) como una forma simbólica que tiene "un rostro doble. Por una parte nos muestra una estructura conceptual y, por otra, una estructura perceptual. No es una mera masa de ideas confusas y sin organización, depende de un modo definido de percepción" (p. 119). Es decir, el mito permite adquirir conocimiento y tener consecuencias prácticas.

Regresando a la idea de la oralidad, el mito se transmitió en los inicios a través de esta vía, siendo parte crucial de la 
vida cotidiana y espiritual de las comunidades, pues en él hallaban las respuestas esenciales que se necesitaban para tener sosiego y permitir la cohesión de la colectividad: "La fuerza de la palabra oral para interiorizar se relaciona de una manera especial con lo sagrado, con las preocupaciones fundamentales de la existencia. En la mayoría de las religiones, la palabra hablada es parte integral en la vida ritual y devota" (Ong, 2016:132). El mito es una narrativa que permite la transmisión y persistencia de historias vitales al ser humano.

Pero, ¿los mitos persisten en la era actual? La respuesta es afirmativa. Aunque han sufrido transformaciones, estos relatos siguen activos y forman parte del imaginario colectivo y personal; acorde al psicólogo estadounidense Rollo May (1992), las personas no podemos desprendernos de ellos, pues forman parte de nuestra esencia:

La necesidad del mito, estará presente allí donde haya personas que se llamen a sí mismas humanas [...] son la autointerpretación de nuestra identidad en relación con el mundo exterior. Son el relato que unifica nuestra sociedad. Son esenciales para el proceso de mantener vivas nuestras almas con el fin de que nos aporten nuevos significados en un mundo difícil y a veces sin sentido. (p.22)

Los mitos han sido degradados por disciplinas como la religión y la ciencia, pero siguen existiendo, ¿acaso, no durante la Alemania nazi se fomentó de cierta manera el mito prometeico, donde Hitler fungió como un Prometeo moderno, libertador que prometió traer el progreso y la gloria a la derrotada Germania posterior a la Primera Guerra Mundial? Las industrias culturales también promueven el mito; se ve en diversas películas, series y dibujos animados que tienen de manera recurrente una figura mítica: el héroe, que dota al relato de aventura, lucha y matices complejos.

A esta persistencia y aparición reinterpretada del mito a través de las diferentes épocas, el antropólogo francés Gilbert Durand (1981) lo conceptualiza como cauce mítico. El objetivo del trabajo presentado es develar una de esas vertientes: el mito dionisiaco ¿a través de qué? De los festivales de música electrónica actuales, teniendo como hipótesis que estos eventos en su dinámica hacen alusión a Dioniso (Baco para los romanos) por la celebración, comunidad y transgresión de valores que manejan.

Los festivales de música electrónica en occidente son una modalidad de espectáculo afamada -hoy en día- en diversos países; consiste en la presentación de diversos $d j$ 's durante varias horas o días en escenarios novedosos y llenos de soportes visuales. Sus antecedentes se remontan a la década de los sesentas y setentas, cuando había eventos similares pero de música rock, como Woodstock en Estados Unidos, o el Festival de la Isla de Wight y el de Glastonbury en Reino Unido.

Para explicar estos sucesos se han seleccionado tres eventos que se celebran a nivel internacional: Electric Daisy Carnival (EDC), Tomorrowland y Burning Man.

\section{Aproximación teórica}

Para poder ahondar en el concepto de cauce mítico, primero habrá que definir ¿qué se entiende por mito? Desde la perspectiva de Rollo May (1992) es "una forma de dar sentido a un mundo que no lo tiene. Los mitos son patrones narrativos que dan significado a nuestra existencia” (p.17), esta definición permite entender al mito como narración ontológica en la vida humana. Se complementa esta noción con las afirmaciones del académico mexicano Julio Amador Bech (2004) quien considera que "los mitos han desempeñado una función esencial en la formación del saber durante milenios [...] son la forma fundamental y originaria de la conciencia vital" (p.15).

Siguiendo las premisas anteriores, se afirma que el mito es explicativo, moldea la realidad y la conducta, además de develar una verdad para aquellos que lo comparten. El filósofo rumano Mircea Eliade (2010), ahonda en esta cuestión de revelación por parte del mito y le añade dos puntos básicos: la polisemia en su interpretación y el acceso a una dimensión sagrada, "es una realidad cultural extremadamente compleja, que puede abordarse e interpretarse en perspectivas múltiples y complementarias [...] revelan una actividad creadora y desvelan la sacralidad [...] el mito se considera como una historia sagrada y, por tanto, una «historia verdadera»" (p. 5).

Los postulados de Eliade conducen a la importancia que tiene el mito en la vida, a pesar de los diferentes mecanismos con los cuales se adquiere y produce conocimiento, reflejados 
en instituciones como la escuela, el gobierno, los medios de comunicación, etc., es decir, los mitos siguen alrededor de nosotros. Dicho sea el caso de la infancia, donde la comunicación oral es fundamental para el desarrollo, y mucha de la información adquirida es gracias a las historias fantásticas que relatadas, y que se conforman en la memoria a modo de mitología. La propia religión no está exenta de un relato mítico, y al profesarse ese credo, también se entra a esa «verdad» interiorizándola en la mente y comportamiento. A su vez, las instituciones -como las antes mencionadas- también recurren al mito para justificar y legitimarse. Un ejemplo es el escudo nacional mexicano que se fundamenta en el mito origen de la fundación de Tenochtitlán.

Pero entonces ¿por qué el mito a veces pareciera tener una connotación negativa en la actualidad? Esto se debe a cómo la tradición judeo-cristiana fue desvalorizando el poder de la tradición mítica y del politeísmo, trasladándolo a una estetización, lo cual se reafirmó tiempo después con la Ilustración, que favoreció el pensamiento racionalista ante cualquier otra vía de comprensión:

En la época de la ciencia en que vivimos, el mito y lo mítico no tienen ningún derecho legítimo $\mathrm{y}$, sin embargo, justamente en esta época de la ciencia se infiltra la palabra griega, elegida para expresar un más allá del saber y de la ciencia en la vida del lenguaje. (Gadamer, 1997: p.23)

El mito continúa siendo una herramienta cognitiva ¿la razón? La mente humana es mitopoyética: se construyen narrativas de manera natural, las representaciones de dicha narración dependen del seno cultural que del que se atañe. La función mitopoyética de la mente "alude a la diversidad de producciones psíquico-culturales enraizadas más en las necesidades vivenciales afectivas [...] denota la incesante actividad generativa de la mente" (Arbiser, 2017: p.141). Así pues, los mitos perseveran hasta nuestros días porque se insertan en la necesidad humana de lo trascendente y de poner orden a lo ambigüo a través de relatos: "Vivimos en un mundo narrado [...] Los humanos somos nuestras historias, y quien renuncia a sus historias, a sus peripecias, renuncia a sí mismo" (Duch, 2008: p.197).

¿A dónde lleva esto? A entender el mito como una estructura que configura la experiencia humana, y que no es un sistema fijo, sino que a lo largo del tiempo se actualiza, modifica y enriquece, derivando en un cauce mítico, definido por Durand como un afluente mitológico que se intersecta de manera compleja en el imaginario actual. Dicho con otras palabras, es una vía diacrónica de interpretación del mito que va tomando forma acorde al contexto donde emerge, pero que permite que dicho relato mítico siga vigente y adhiriéndose a nuevas épocas.

\section{Metodología}

Con el fin de rastrear el cauce mítico dionisiaco de los festivales de música electrónica se echará mano de la hermenéutica analógica del filósofo mexicano Mauricio Beuchot (2018), quien define esta aproximación teórica como una conjunción entre el pensamiento crítico de la razón y la creatividad de la imagen simbólica:

Una hermenéutica analógica supera la hermenéutica unívoca del cientificismo, porque no tiene esas pretensiones de claridad y distinción en la comprensión de los textos, no incurre en ese absolutismo que es del todo ilusorio. Pero no por ello se derrumba en una hermenéutica equívoca [...] ya que no cae en el desencanto que produce la completa diferencia, la plena ambigüedad, escapa al relativismo extremo y puede ofrecer al mismo tiempo apertura y seriedad [...] propicia que se dé una comprensión compartida entre el autor y lector. (p.48)

Beuchot (2018), retoma postulados de C.S. Peirce y H.G. Gadamer en su hermenéutica, además de tender puentes entre el discurso mítico-religioso y el discurso lógico-racional, donde no se cae en un relativismo sino que pretende una verdad, la cual "exige la coherencia, correspondencia, como explicación del consenso que se obtiene del diálogo. Una hermenéutica analógica puede ser clave en el diálogo intercultural, porque ayudará a respetar las diferencias, incluso a privilegiarlas, pero sin perder la capacidad, por la semejanza" (Beuchot, 2018: p.49).

El cauce mítico se entiende en lo intercultural, en la mezcla de visiones del mundo a través del tiempo, teniendo 
como hilo conductor el mito. La propuesta de Mauricio Beuchot (2018), permitirá hallar las semejanzas del mito dionisiaco con los festivales de música electrónica, pero a su vez distinguir sus diferencias y divergencias.

Un poco de contexto: Dioniso es una divinidad de gran complejidad, que tiene diversas acepciones, acorde a la tradición desde donde sea contada la historia. Dentro de la mitología griega antigua, fue hijo de Zeus y Sémele ${ }^{1}$, una mortal hija de los reyes de Tebas (Cadmo y Harmonia), pero la consorte de Zeus, Hera, urdió un plan para terminar con el romance, Sémele muere y su hijo nonato (Dioniso) es rescatado por su padre (escondiéndolo hasta su nacimiento en su muslo) para después ser transformado por su abuela (Rea) en un carnero para esconderlo de la furia de Hera.

Al crecer, Dioniso se embarca en una serie de viajes por el Mediterráneo, en los cuales profesa diversos excesos en compañía de Sileno, sátiros y las Ménades. Durante su travesía enseña a sus seguidores cómo cosechar las uvas y transformar su jugo en vino, por lo que cobra mucha popularidad. Contrae nupcias con Ariadna, diosa egea de la vegetación y desciende a los infiernos en busca de su madre.

A Dioniso se le vincula como divinidad de la vegetación, de la vid, del vino, de los frutos, del renuevo estacional, del júbilo, de la fecundidad, del deseo, del éxtasis, liberador de los infiernos (puede estar en el inframundo como en el ámbito terrenal y celestial), de la anarquía, de los estados irracionales y alterados, patrón de los actores y de lo festivo (Wilkinson, 2009: p.34).

Observando estos atributos es más claro el cauce mítico que debe explorarse a través del estudio de caso elegido: los festivales de música electrónica son herencia de la contracultura surgida en la década de los 60, donde el movimiento psicodélico, hippie, estudiantil y de otros grupos sociales como la comunidad afroamericana y la LGBT+, permitieron una transgresión del orden y un llamado a la transvaloración de los sistemas de pensamiento vigentes. La llamada revolución sexual, que se continúo durante los años 70 en todo el mundo, es una veta dionisiaca que emula la exaltación frenética de la sexualidad y el placer sobre el cuerpo que antaño se reflejaba en las celebraciones al dios griego llamadas bacanales.

\footnotetext{
${ }^{1}$ En algunos relatos se dice que era hijo de Perséfone y Zeus.
}

Se acaba de mencionar el término «veta» que dentro del asunto de los cauces míticos, Durand lo entiende como una derivación que surge del mito origen (el cual es inahaprensible en su totalidad) y que continúa a través del tiempo expresándose en diversas formas. El autor francés también añade el término de cuenca semántica que "indican génesis y declives de los mitos [...] no es una estructura instantánea y rígida, se escalona en seis fases [arroyo, partición de las aguas, confluencias, nombre del río, acondicionamiento de las orillas, deltas y meandros]" (2012 :pp.106,116), de tal suerte, un cauce mítico (presencia latente del mito) también confluye en una cuenca semántica, que manifiesta el desarrollo exponencial de un mito a lo largo de la historia, es decir, una cuenca semántica permite ver la robustez de un mito a partir de su aparición como un cauce, el cual va manifestarse a través de vetas (Ver Figura 1).

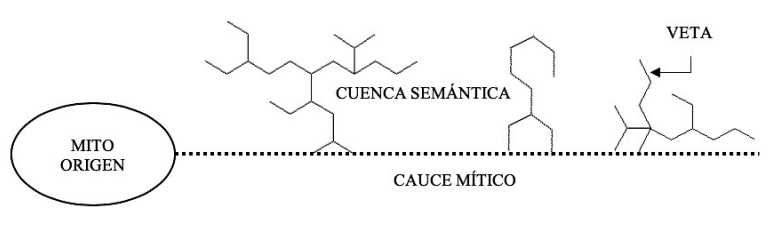

Figura 1. Modelo de cauce, cuenca y veta mítica. Elaboración propia.

Siguiendo con el cauce mítico de Dioniso y su huella en el tiempo presente a través de los festivales, es pertinente observar cómo esta deidad se le relaciona con:

La emancipación, la supresión de las prohibiciones y de los tabúes, el dios de los desfogues y de la exuberancia. «Lo propio de la purificación dionisíaca, dice P. Boyancé, es llevar a su límite aquello de lo que hay que liberar al alma». (Chevalier, 1986: p.421)

Tales ideas acercan a lo que sucede durante la celebración de esa clase de eventos, pues en ellos hay una catarsis al orden cotidiano, sus propios discursos mediáticos fomentan esta idea de liberación no solo del cuerpo, sino también del espíritu ${ }^{2}$.

Se habló en páginas previas de los festivales que se tomarán como referencia para escudriñar el cauce dionisiaco:

\footnotetext{
${ }^{2}$ Vid. YouTube (2012) "Q-dance at EDC Las Vegas I Official Q-dance Aftermovie". Channel Q-Dance. 13 Julio 2012. Disponible en: https: //youtu.be/ty_3egPmXzE.
} 
Tomorrowland, Burning Man y EDC, este último es el único que se celebra en México desde el 2014, teniendo un récord en 2019 de asistencia de 225,000 personas, lo cual lo hace el segundo $E D C$ más importante a nivel mundial, por detrás de la sede, que es en la ciudad de Las Vegas, USA. La siguiente tabla resume los datos de cada festival del corpus.

¿Por qué escoger esos tres y no otros entre toda la amplia gama que existe de festivales de música electrónica a nivel nacional e internacional? La razón se centra en que los eventos seleccionados tienen una constante: más que espectáculos, se consideran experiencias, es decir, no depende su estructura tanto del talento ( $d j$ 's $)$ sino de generar un espacio común para los asistentes donde se produzcan recuerdos, comunidad y una atmósfera irrepetible. Lo anterior, a partir de los estímulos que presentan más allá de la música: instalaciones artísticas, escenarios vanguardistas, baile, performance, acróbatas, juegos mecánicos, pirotecnia, food trucks, áreas de descanso, áreas VIP, juegos de luces, fuego y lásers. Asimismo, manejan temáticas que configuran todo el festival y es aquí donde el mito como veta se hace presente, pues su discurso y filosofía que les caracteriza tiene un trasfondo mítico que vale la pena explorar.

Las categorías que se han establecido para poder analizar el previo corpus son: 1) ciclo: permitirá saber la periodicidad del evento, donde a través de un mecanismo ritualizado y repetitivo fija la narrativa mítica; 2 ) relato: cada festival tiene una trama singular que lo sustenta, dentro de ella se patentiza el cauce mítico dionisiaco que permite una catarsis con los asistentes al conllevar identificación con lo que se presenta; 3) ambiente: si hay un ritual inserto, la manera de reforzarlo es a partir de la construcción de una atmósfera, que se logra con la unión de la infraestructura (escenarios, luces, instalaciones, dj's) y las prácticas de los asistentes, generando un curso de energía e intercambio simbólico muy importante; y 4) filosofía de pensamiento: tanto el relato como el ambiente se ven fortalecidos con la serie de valores que cada festival maneja de forma muy peculiar. Hay ciertas directrices en cada uno que hacen una experiencia única el asistir a ellos, además que fomentan una cohesión colectiva y la identidad individual. Estos cuatro indicadores se diseñaron acorde la estructura que comparten los tres festivales seleccionados, que aunque tienen una dinámica peculiar, hay ciertas constantes en su organización que permite rastrear el cauce mítico dionisiaco.
Para Julio Amador (2004), el mito cumple cuatro funciones: cognoscitiva, ontológica, psicológica y moral, social y política. La primera permite entender elementos básicos de la existencia y a través del lenguaje ir adquiriendo conocimientos de nuestro entorno. La función ontológica va más hacia la explicación de una cosmovisión y de símbolos universales comunes al humano. Mientras que la dimensión psicológica y moral "pone de manifiesto los conflictos de la vida humana, la relación entre la vida interior y el mundo" (Amador, 2004: p.20). La función social y política "crea códigos de identidad comunitaria, unifica las creencias de un grupo, permite la integración social, fundamenta y legitima estructuras sociales" (Amador, 2004).

La clasificación de Julio Amador (2004), nos da la relevancia que tiene el mito aún en la actualidad (reflexiónese en los mitos que rodean al Estado o a la figura presidencial). A la vez, se introduce en el papel medular que tuvo el mito en sociedades tradicionales, pues permitía estructurar de manera global toda la vida social y personal, era, en pocas palabras, una guía heurística de la existencia.

Empero, en el análisis realizado del cauce dionisiaco al corpus a través de la hermenéutica analógica, las funciones que se destacaron fueron las dos últimas propuestas por Amador (2004), debido a que son las que sustentan con mayor potencia la presencia del mito de Dioniso en los festivales seleccionados.

\section{Resultados}

Una de las primeras vías para enlazar los festivales con un cauce mítico, es a través de la idea de Mircea Eliade (2010) sobre cómo el mito en cuanto a conocimiento "se vive ritualmente y se narra ceremonialmente [...] expresa, realza y codifica las creencias, salvaguarda los principios morales y los impone" (pp. 10-11). Estos eventos tienen una naturaleza en el ritual, se configuran cíclicamente, manejan un relato, además de tener un ambiente ceremonial y una filosofía 
Tabla 1. Descripción del corpus.

\begin{tabular}{ll}
\hline Festival & \multicolumn{1}{c}{ Descripción } \\
\hline Tomorrowland & Origen y sede: Boom, Bélgica (2005). \\
& Sedes alternas: Alpe d'Huez, Francia. \\
& Georgia, USA. Sao Paulo, Brasil. \\
\hline Electric Daisy Carnival (EDC) & Se celebra anualmente durante el verano en Bélgica \\
& y en los Alpes Franceses durante marzo. \\
& Origen: Los Ángeles, EUA (1997). \\
& Sede Principal: Las Vegas, Nevada. EUA. \\
& Sede Nacional: Ciudad de México. \\
& Sedes alternas: Japón, Corea, China, India, \\
& Londres, Nueva York, Orlando. \\
& Se celebra anualmente en la Ciudad de México a \\
& finales de Febrero y en las Vegas en mayo. \\
\hline Burning Man & Origen: San Francisco, EUA (1986). \\
& Sede actual: Desierto Black Rock. \\
& Nevada, Estados Unidos. \\
& Se celebra anualmente en agosto/septiembre. \\
\hline
\end{tabular}

de pensamiento basado en el PLUR ${ }^{3}$ (Paz, Amor, Unidad y Respeto).

A partir de las previas afirmaciones, se hará pertinente el análisis a través de la hermenéutica analógica de Beuchot: se comenzará con el desarrollo en cada evento de las 4 unidades descritas, ciclo, relato, ambiente y filosofía de pensamiento. Posterior se hará una tabla donde se mencionen las funciones descritas por Julio Amador (2004) acerca del mito y la manera en que estos festivales lo promueven. Para terminar se hará una explicación general sobre la manera en que el cauce mítico dionisiaco sigue vigente en estas celebraciones a partir de establecer cuencas semánticas y vetas.

\section{1) Tomorrowland}

Ciclo: como puede verse en la tabla 1 , su ciclo es anual, dividido en dos fechas, la más importante es la de verano, que

${ }^{3}$ El PLUR es un acrónimo de las palabras Peace, Love, Unite and Respect; surgió en la escena rave de fines de la década de los ochenta e inicio de los noventa. Tanto en Reino Unido como en Estados Unidos, se adhirió a géneros de electrónica tales como el techno y el house. En la actualidad, la mayor parte de festivales fomentan esta filosofía que se ha transformado en un estilo de vida para muchos de los asistentes, como en los llamados Kandi Kids que establecen prácticas dentro de los eventos como su llamativa vestimienta y regalar brazaletes, los cuales deben incluir un saludo que promueve esos valores a través de ciertos movimientos con las manos. Uno de los $d j$ 's que ha hablado sobre los orígenes del PLUR es Frankie Bones, quien afirma que su uso se gestó en la costa este de Estados Unidos, en específico, Nueva York, donde diversos clubes tocaban música electrónica transformándose en todo un fenómeno, y para promover estas celebraciones se les ocurrió una idea "El cuatro de julio de 1990. Íbamos a pintar los vagones del metro con el mensaje "Paz, amor y unidad". Ese fue el movimiento" (Bones F., citado por Sterling S., 2016). comenzó con un solo día de celebración extendiéndose en la actualidad a seis. Su sede en los Alpes franceses comenzó en 2019 y coincide con el inicio de la primavera.

Relato: maneja un discurso de fantasía, donde los asistentes entran a un sitio excepcional, en el cual la magia, el amor y la unidad se harán presentes. Los escenarios también van acorde a esta narrativa, siendo el main stage caracterizado con diversos motivos como deidades del bosque, astros (sol, luna, estrellas, arcoiris, nubes), animales o temáticas enteras como en 2012 con The Book of Wisdom, que era una biblioteca que en el centro tenía un libro abierto con rasgos antropomórficos; The Arising of Life (2013) con caracterización de un entorno prehistórico lleno de cascadas, vegetación exuberante y un volcán en erupción; Amicorum Spectaculum (2017) con alusión circense, donde el escenario se transformó en una carpa llena de acróbatas; y en 2018 llegó The Story of Planaxis, un extraordinario mundo acuático, engalanado por corales, peceras y un enorme caballito de mar.

Ambiente: es un festival con gran infraestructura que promueve la unión de su comunidad. Organiza vuelos para llevar a los asistentes a la sede en Boom. A su vez tiene un área llamada Dreamville en la cual puedes encontrar varias opciones de alojamiento: camping, habitaciones, cabañas. Aquí también hay un supermercado y otros locales comerciales. El agua potable es gratuita y existen zonas para cargar los dispositivos electrónicos. Las personas que acuden 
son de diversas nacionalidades y esto es patente a través de las múltiples banderas que se observan durante la celebración. Por lo general hay un entorno de respeto y camaradería. Tienen una política de cero tolerancia de consumo de drogas, fomentan el reciclaje y la no-violencia.

Filosofía: busca crear un mundo provisional lleno de magia y comunión con el entorno que sirva como reflexión -y acción- para la vida cotidiana, en palabras de los organizadores: "crear una realidad que se relacione positivamente con la madre naturaleza y contribuya al bienestar de las próximas generaciones. Comprometámonos y hagamos algo bueno hoy, por lo que estaremos agradecidos por el mañana" (Tomorrowland, 2019). También busca crear unidad a través de lo cosmopolita que es el evento, y lograr que sin importar la nacionalidad todos estén hermanados por unos instantes. Su eslogan es: "Live Today, Love Tomorrow, Unite Forever" (Vive ahora, ama mañana, unidos por siempre), lo cual va de la mano del PLUR.

\section{2) Electric Daisy Carnival (EDC)}

Ciclo: anual y, dependiendo de la sede, es la fecha en la cual se celebra. Por ejemplo en nuestro país es a finales del mes de febrero, durante la época de cierre del invierno. Pero en otros lugares como Las Vegas, EUA, se realiza durante mayo, en plena primavera. En la ciudad de Guangdong, China; lo celebran al fin del otoño en el mes de noviembre.

Relato: en todos sus contenidos y dentro del mismo festival su narrativa gira en torno a que se deje atrás -temporalmente- la cotidianidad y que en ese lugar podrás sentirte tú mismo, acompañado de otras personas que también buscan liberarse y experimentar un mundo bajo el «cielo eléctrico» lleno de color, luz y fraternidad. En el trailer 2016 de Las Vegas ${ }^{4}$ su discurso es patente: son los 20 años de $E D C$, y la historia que presenta el video es un desierto en el cual surge un oasis, que es el festival, para después presentar escenas de diversas ediciones donde se muestra la euforia, unión, alegría y recursos del evento. Esto último es vital, Electric Daisy funciona como un pequeño reino de ensueño, donde sus escenarios son comarcas con su propia lógica y atmósfera; se pueden resaltar: Kinetic Field, que es el main

\footnotetext{
${ }^{4}$ Vid. YouTube (2016) "EDC Las Vegas 2016 Official Trailer". Channel Insomniac Events. 28 Abril 2016. Disponible en: https : / / youtu. be/Z o 47D-ZeMmI.
}

stage y al igual que en Tomorrowland maneja temáticas; Kinetic Cathedral (2014) donde una iglesia gótica transformó el paisaje; Kinetic Love (2018) en el cual titanes sostenían un corazón que latía al ritmo de los beats; Crystal Village (2015) en el que los cuatro elementos eje de la naturaleza se reunieron en un escenario lleno de cascadas, dragones y búhos; Kinetic Gaia (2017) una diosa madre que abría sus brazos a los asistentes. A su vez, otros escenarios como Neon Garden donde las buenas vibras son la constante; Wasteland un lugar no apto para los débiles con ambiente apocalíptico; Circuit Grounds donde los avances tecnológicos hacen una noche inolvidable, son los que permiten que el relato de $E D C$ se fortalezca, brindando una experiencia más allá de la música, haciendo que el papel del asistente tenga un papel medular, en el trailer antes mencionado, el material cierra diciendo “Gracias por 20 años de $E D C$, tú eres la magia, inspiración y amor detrás de todo. Ustedes son las estrellas que construyen el cielo eléctrico. Que esta luz brille intensa todo el tiempo". El relato de este festival se gesta no solo dentro del evento, sino que también se desarrolla a través de sus canales oficiales en redes sociales digitales, donde en sitios como Instagram, Twitter y Facebook, fomentan una narrativa que sea inclusiva, generadora de comunidad y que vaya acorde a la cultura donde se está promocionando. Un ejemplo: en la marcha del Orgullo LGBTTTI 2019, en la Ciudad de México, el EDC tuvo una colaboración con un carro alegórico y, dentro de sus redes, no desaprovechó la oportunidad de hacer patente su "compromiso" con la comunidad mexicana LGBT+.

Ambiente: en su página oficial, tienen la encomienda de transmitir energía positiva a los asistentes como «moneda de cambio». Lo anterior orienta a cómo es la atmósfera que pretenden los organizadores construir a través de atracciones como juegos mecánicos e instalaciones artísticas: desde el momento que entras al festival, los sentidos se ven bombardeados con diversos estímulos y vibrantes colores que te invitan a sumergirte en un entorno de celebración y regocijo. Las personas que asisten a $E D C$ por lo general tienen una conducta armónica, donde los incidentes son mínimos. En el caso de la edición mexicana, Ocesa, la empresa intermediaria con Insomniac Events (responsables y fundadores del evento) no reportó en 2019 ningún conato grave en los seis años que lleva celebrándose en el país. A su vez promueven el cuidado al ambiente y la integridad: no tirar basura, agua 
potable gratuita, no vender alcohol a menores de edad y cero tolerancia a las drogas.

Filosofía: el fundador de EDC y CEO de Insomniac Events y Pasquale Rotella, tiene muy claras las directrices del festival a través de valores como el arte, la vida, el amor y la música dance. Su eslogan es: "aquí todos son bienvenidos" y esto lo hacen patente en todos sus discursos donde hacen una invitación para todo aquel o aquella que desee entrar a ese mundo. En su sitio web hay una sección titulada «En lo que creemos» y ahí muestran el sistema de ideas que ostentan de manera muy clara:

Creamos experiencias inolvidables impulsadas por la imaginación y positividad [...] amor, cuidado y conexión por sobre todo [...] construido en la inclusividad, nuestra comunidad representa unidad, celebrando y recibiendo a todos. No importa tu forma, tamaño o color. Creatividad en todo lo que hacemos, No vemos límites en lo que podemos crear, y tampoco tú deberías hacerlo. No buscamos tendencias, creamos cultura. Traspasamos los límites para hacer cosas que nunca has experimentado antes. (EDC México, 2019)

\section{3) Burning Man}

Ciclo: anual, se hace a fines de agosto o principios de septiembre en el desierto de Black Rock, Nevada. Durante nueve días se congregan los asistentes, las fechas para el 2019 van de agosto 25 a septiembre 2 .

Relato: Burning Man es un festival fuera de lo común, pues no se denomina en esta categoría, en su sitio web afirman: “Burning Man no es un festival! Es una ciudad donde casi todo lo que sucede es creado en su totalidad por sus ciudadanos, que son participantes activos en la experiencia" (Burning Man, 2019); desde su fundación en 1986 ha buscado crear una comunidad autosustentable dentro del desierto de Nevada, para tal fin, cada año se construye una ciudad llamada Black Rock City, en la que no se maneja dinero, marcas o patrocinios. Las personas deben llevar sus propios recursos para sobrevivir; dentro del evento hay algunos servicios básicos para la comunidad como sanitarios, hielo, café, asistencia a vehículos y control de emergencias. También se maneja el trueque o regalar insumos. La infraestructura de servicios corre a cargo de voluntarios.

El nombre del «festival» se debe a un ritual que se realiza la última noche: se quema un afiche de varios metros de altura; otra política dentro de su discurso es que no deben dejar rastros los asistentes de su presencia, es decir, deben recoger todos sus desechos y demás enseres -conocidos como MOOP (Matter Out of Place) para que la zona de Black Rock City quede impoluta, el reciclaje y cuidado al ambiente es primordial. Otro aspecto clave es la promoción del arte, se hace una invitación a que las personas exploten su imaginación de manera amateur o que artistas emergentes exhiban su obra a través de instalaciones, vehículos llamados «mutantes» o actividades culturales diversas.

Ambiente: se promueve una cultura participativa (asisten cada año alrededor de 69,000 personas) donde a partir de la unión y apoyo mutuo se hace posible la manutención de la ciudad de Black Rock. Las actividades artísticas son gratuitas, cualquier persona puede agendar su asistencia a cada una de ellas. Los que acuden saben que es una travesía llegar a Burning Man (hay que atravesar grandes distancias en el desierto, y esperar un tiempo considerable para poder instalarse a totalidad, pues se hacen filas de automóviles ingresando a la zona) por lo que los asistentes se han bautizado a sí mismos como «burners» y hay un notorio clima de camaradería, en el sitio web se enuncia:

Desde sus primeros días, Burning Man ha sido un esfuerzo de colaboración, reuniendo a personas con diferentes antecedentes, intereses, perspectivas y habilidades. Hoy en día, esta creciente comunidad sirve como una red vibrante que conecta a personas, agrupaciones, eventos $\mathrm{y}$ organizaciones de todo el mundo. (Burning Man, 2019)

Filosofía: está fundamentada en diez principios que son; inclusión radical, donación, desincorporación (mercantil), autosuficiencia radical, autoexpresión radical, esfuerzo comunal, no dejar rastros (desechos), responsabilidad cívica, participación e inmediación (comunicación cara a cara). Asimismo, buscan que el mundo sea un lugar más creativo y conectado a través de difundir la cultura que surge como parte del proyecto de Burning Man. Su visión es "traer experiencias 
a personas de maneras grandiosas, inspiradoras y alegres que elevan el espíritu humano, aborden los problemas sociales e inspiran un sentido de cultura, comunidad y compromiso cívico" (Burning Man, 2019), y durante el evento manejan áreas de trabajo a través de arte, educación, filosofía y autosustentabilidad para provocar que saliendo de ahí la experiencia se transforme en un estilo de vida permanente.

Con estos hallazgos, partiendo de la hermenéutica analógica de Beuchot (2018) y las cuatro categorías que se dispusieron para encontrar similitudes y diferencias, se puede afirmar que hay una cierta constante en todos los festivales: hacen uso de una narrativa mítica, de prácticas/rituales y, sobre todo, establecen un espacio para generar un intercambio de significados sustancial que va dirigido a ciertos aspectos de la realidad humana: la unión con el otro, la búsqueda de identidad, empatía con el entorno, liberación de emociones, sensaciones extáticas, plenitud del ser. Elementos que pueden asociarse al mito de Dioniso. Por lo que es pertinente retomar lo postulado de J. Amador (2004) sobre las dimensiones del mito y ver cómo se insertan en dichos eventos, la siguiente tabla describirá estas aproximaciones:

Tomorrowland, en su relato, pretende mejorar el mundo a partir de fomentar un compromiso y responsabilidad con la «madre naturaleza» y las nuevas generaciones; se autonombran a los asistentes como "Gente del mañana". Hay una orientación a ser como se tiene que ser, personas que disfrutan su vida (mito dionisiaco) pero fuera de los excesos banales, se pretende cobrar conciencia de lo que sucede hoy en día en la realidad cotidiana. Busca una cohesión a partir de su infraestructura como es Dreamville, zona de hospedaje que funciona como una pequeña aldea en la que puedes hallar diversos servicios para facilitar tu estadía, además de promover actividades de integración, en su página menciona que no es solo un área de camping, sino una oportunidad de compartir experiencias y crear amigos.

Sus escenarios siempre buscan compartir mensajes de unión y reflexión para mejorar las condiciones en las que se encuentra el mundo. Asimismo, cuentan con dos proyectos altruistas a partir de Tomorrowland Foundation, que busca apoyar a niñas y niños a través de educación y las artes, comenzando un programa en Nepal llamado Music \& Arts School, y Mobile School enfocado en jóvenes en situación de calle. Por último, en su sitio web, hay una plataforma titulada
Love Tomorrow que tiene como misión impulsar el desarrollo sustentable a partir de cuatro valores: naturaleza, innovación, salud y respeto.

$E D C$ tiene una gran labor mítica dirigida al inconsciente, en primer lugar, su slogan: aquí todos son bienvenidos, crea identidad con aquellos que se sienten desprotegidos en otras esferas sociales. La energía producida en el festival a través de la convivencia, baile y música se ostenta como lazo de unión, a manera de un espíritu colectivo o ethos: "Imaginación y energía positiva son la moneda de cambio en este lugar' (EDC Mx, 2019). Sus tráileres son muy potentes en ese aspecto, ofreciendo imágenes y un discurso que propone armonizar el caos cotidiano. Al igual que Tomorrowland, hace una gran labor discursiva dentro y fuera del evento. Todos los promocionales de EDC manejan mensajes adheridos al PLUR y a su propia filosofía como: amor, cuidado y conexión por el otro, inclusividad, creatividad, tomar riesgos y romper reglas; además de los elementos ideológicos que tienen como eje: vida, amor, arte y música. Su fundador, Pasquale Rotella, siempre busca crear una conexión con la audiencia, al adaptarse a las tradiciones locales de las sedes, a su vez, en sus redes sociales hay una continua actividad para impulsar la retroalimentación e interés.

Burning Man (BM) establece con sus diez principios toda una estructura psicológica y moral para sus asistentes, muchos de ellos, tomándolos como una filosofía para su vida fuera del evento. En su sitio oficial, el artista estadounidense, Larry Harvey menciona: "Black Rock nos da la oportunidad de sanar, de convertirnos en nosotros mismos". Se autonombra $B M$ como una cultura de posibilidades, donde también hay un ethos que es el corazón de su comunidad y de la memoria que van creando desde 1986, consideran que pueden producir un cambio espiritual y a partir de la inmediatez y la autosustentabilidad promover una transformación en cómo se entiende la vida humana.

$B M$ es uno de los festivales con mayor función social-política, debido a que ellos pretenden generar un cambio sustancial en el mundo. Tienen una agenda hacia el 2030 que ambiciona lograr soluciones sobre el tema de la sostenibilidad del medio ambiente ¿Cómo? A partir de que la comunidad de Burners extienda sus acciones más allá de su estadía en Black Rock City, y que la cultura que se gesta dentro del evento se transforme en un estilo de vida permanente. Y 
Tabla 2. Dimensiones del mito propuestas por Amador (2004) presentes en los festivales.

Pscológica-moral Social-política

Los tres festivales establecen una serie de valores que orientan de forma teleológica a los asistentes. La narrativa mítica establece cierta filosofía que cambia no solo a corto plazo, sino que hay una adopción como estilo de vida en muchos de ellos, donde, a partir de la creación de símbolos en común, se ofrece una idea de orden y armonía ante el desasosiego, caos y apatía del mundo cotidiano.
Tanto los contenidos promocionales de cada evento, como la infraestructura y organización buscan crear códigos de integración que permita la permanencia del festival, pero no solo eso, sino que cada uno de ellos tiene una agenda muy específica para promover acciones de cambio en los entornos donde se presenta, ya sea para fomentar el cuidado del medio ambiente, inclusión, espiritualidad, etc. tienen en mente crear una red que incluya organizaciones a nivel mundial que se unan a su filosofía.

Es momento de ahondar en el objetivo de la investigación: el cauce mítico dionisíaco presente en estos espectáculos. Se tomará como referencia la Figura 1, donde el mito origen es el de Dioniso -previamente explicado-, para después brevemente desarrollar el cauce mítico de esta divinidad a partir de inicios del siglo XIX hasta llegar a la cuenca semántica que ostenta la veta que representa cada festival, y las razones de su integración al cauce a través de la hermenéutica analógica de Beuchot (Ver Figura 2).

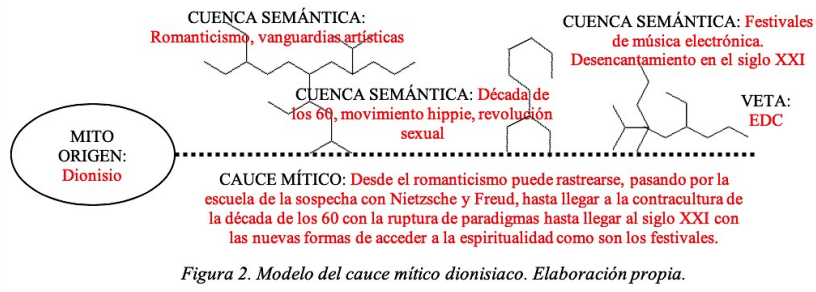

Dioniso se caracteriza por la transgresión a la moral cotidiana y el paroxismo salvaje, actitudes que durante siglos fueron reprimidas en la sociedad occidental por la iglesia, el Estado y el pensamiento cientificista e ilustrado; hasta que llegó el movimiento artístico del romanticismo a fines del siglo XVIII, donde sus representantes quebrantaron los valores vigentes e hicieron todo un cuestionamiento a las instituciones de la época, a partir de ahí otras corrientes como el realismo, simbolismo y posterior las vanguardias del siglo $\mathrm{XX}$, trajeron una desavenencia con el sistema existente.

Los dos conflictos bélicos mundiales hicieron que las personas se preguntaran sobre las aparentes ventajas del llamado «progreso» y surgieron corrientes como el existencialismo y el psicoanálisis, donde representantes de la llamada Escuela de la sospecha, como Freud y Nietzsche, ahondaban en la descomposición social a través del estudio de la cultura y la subjetividad del ser humano:

Dioniso es una de las figuras nietzschianas de la vida, opuesta al prudente aspecto apolíneo. Simboliza las fuerzas obscuras que surgen de lo inconsciente; es el dios que preside los desenfrenos que produce la embriaguez, todas las formas de la embriaguez. (Chevalier, 1986: 421)

También en la actualidad brotaron nuevos géneros musicales como el tango y el jazz, producto de la interacción que tenían grupos sociales marginados, esto es una veta dionisiaca, pues conllevaba una ruptura del orden a través de lo festivo. Lo mismo con la Enmienda XVIII que prohibía la venta de alcohol en Estados Unidos durante los años 20.

Entrada la posguerra, el imaginario colectivo sufrió un profundo cambio. A inicios de la década de los 60 surgieron movimientos contraculturales que alteraron la percepción de numerosos nichos: educativo, el rol de la mujer, minorías, sindicatos, entre muchos más, que comenzaron a interpelar las estructuras hegemónicas; y esto es parte del cauce dionisiaco, pues dicho deidad "simboliza la ruptura de las inhibiciones, de las represiones, de los rechazos" (Chevalier, 1986), y aquí aparecen festivales de música importantes que marcarían la pauta para los contemporáneos: Woodstock en Bethel, Nueva York, EUA; el Festival Glastonbury de las Artes escénicas contemporáneas en Somerset, Inglaterra y el Festival Rock y Ruedas de Avándaro, en Valle de Bravo, México. Estos 
eventos fomentaron el espíritu colectivo y reivindicaron una cuenca semántica sobre el mito de Dioniso al motivar la liviandad de las emociones y la conducta a través del consumo de sustancias como el LSD, mescalina, psilocibina y THC. El sociólogo francés Maffesoli (2012) lo preveía:

A finales de los años setenta anuncié el retorno de Dionisios, dios de la orgía, insistiendo en el papel, cada vez más importante, que la pasión iba a tener en nuestras sociedades [... esta energía se expresa en la búsqueda de un hedonismo refinado. (p.211)

Los años 80 conllevaron la ruptura de paradigmas, es aquí donde emergen géneros como el acid house que se transformó en el estandarte de varios jóvenes en Reino Unido y Alemania, los cuales se congregaban en reuniones clandestinas, al margen de la ley para escapar del asfixiante sistema político, y es ahí donde surgen los raves, antesala underground de los festivales comerciales de hoy en día, que condujeron a un desahogo del agobio, pero también un enardecimiento de los sentidos pues se fomentó el consumo de drogas como el éxtasis mejor conocido como MDMA.

Hoy en día se vive una época donde hay una crisis de espiritualidad grande, la iglesia católica busca maneras para seguir congregando adeptos, mientras que el mundo se vuelca en crisis económicas y políticas, donde el terrorismo, pobreza, mercantilismo y el deterioro del ambiente son constantes. Es en este escenario donde los festivales del corpus subsisten, en gran parte se debe al cauce mítico dionisiaco que preservan y que alrededor de ellos hay numerosos tabúes, tal cual antaño. $\mathrm{Su}$ concepto se inserta en ser válvulas de escape que exalten la necesidad de hacer comunidad a través del festejo. Ahora bien, en las llamadas bacanales ${ }^{5}$ que se celebraban en Roma alrededor del año 186 a.C., fueron estigmatizadas debido a nuevas reglas dentro del senado, que buscaban disciplina y rigor en la sociedad:

\footnotetext{
${ }^{5}$ Las bacanales -antes llamadas oribasia- son fiestas rituales en honor a Baco o Líber (Dioniso para los griegos) donde se emula el trance de las Bacantes o ninfas en el bosque que se entregaban al frenesí, celebrando la vida del dios, al cual cuidaron durante su infancia, protegiéndolo de Hera, en compañía de sátiros y silenos; y que posteriormente, en los viajes de Dioniso fueron adoptados en diferentes regiones como parte al culto que se instauraba en su honor. En Italia también se les nombró fiesta de las Liberalias. (Fernández, 2018: 12)
}

Llegó el momento de ocuparse de los asuntos internos, de infundir orden y afianzar el control social y religioso dentro de los territorios dominados por la República. Cuando el Senado decida emprender una investigación, el foco de las pesquisas $[\ldots]$ se orienta a desvelar qué estaba cambiando recientemente en la praxis religiosa de Baco [...] se decreta un estado de excepción que desencadena la caza de brujas: no se trata solo de perversiones religiosas, sino también de enemigos del Estado. (Fernández, 2018: pp. 6-7)

Se persiguió a los adeptos de Baco por estar al margen de las ideas imperantes, y a sus celebraciones se les dotó de estereotipos oscurantistas -que continúan- como lugar donde se practican excesos, inmoralidad, depravaciones, promiscuidad y que ponían en peligro a las generaciones jóvenes. ¿Acaso esto no recuerda el hostigamiento en Reino Unido hacia los raves, que derivó en la promulgación de la Ley de Justicia Penal y Orden Público de 1994 en la que se prohibían ciertas conductas que -consideraban- iban en detrimento a la sociedad, como fiestas al aire libre donde se congregaran más de 20 personas a escuchar "beats repetitivos".

Tomorrowland, EDC y Burning Man no se libran de estos prejuicios, se les considera por algunos sectores de la sociedad como lugares donde se promueve el uso de drogas y el libertinaje; sin detenerse a investigar un poco más sobre los mismos y su complejo discurso, que tiene raíces mitológicas. Fomentando la función psicológica-moral y social-política de las que habla J. Amador (2004), ejemplo son los tráileres de Tomorrowland (2014) y EDC las Vegas $(2017)^{6}$, en el primero ahondan en un elixir de la vida que une el pasado, presente y futuro, todo dentro de un escenario boscoso que nos conecta a todos; mientras EDC habla sobre rituales que nos unen dando sentido a la vida y cómo se deben congregar en lugares como el festival que son santuarios para compartir con otros.

\footnotetext{
${ }^{6}$ Vid. YouTube (2016) "Tomorrowland 2016 I Introduction Trailer The Elixir of Life". Channel Tomorrowland. 5 Julio 2016. Disponible en: https : //youtu.be/pliBB2la3n8 YouTube (2017) "EDC Las Vegas 2017 Official Trailer". Channel Insomniac Events. 6 Abril 2017. Disponible en: https: / / youtu.be/LzuHNfzdx I I
} 
Pero no todo en el cauce dionisiaco es armonía, también hay una arista lóbrega respecto a los festivales estudiados, los cuales pueden caer en una degradación de su objetivo original, y llegar a conductas vacías de significado, donde pueden imperar abusos, consumismo, hedonismo fatuo y faltas de respeto al otro. Como menciona Nietzsche (citado por Barelli, 2017:p.66) en sus Fragmentos póstumos, Dioniso puede ser educador y creador, pero a la vez engañador $\mathrm{y}$ destructor.

El retorno al culto mistérico de Dioniso tiene una delgada línea entre la euforia y la barbarie; es decir, no todo es miel sobre hojuelas, hay también un lado caótico y de excesos, que ha hecho replantearse la promoción de estos eventos. Como ejemplo se podría citar la muerte por sobredosis de Sasha Rodríguez en 2010 durante el EDC en la ciudad de Los Angeles, suceso que hizo la sede del festival se cambiara a Las Vegas y se restringiera la entrada a mayores de edad, o en Playa del Carmen, México, durante la clausura del festival BMP en 2017, se produjo un tiroteo que cobró la vida de cinco personas, razón por la cual se suspendió la celebración de BMP en territorio mexicano. Es así que surgen estereotipos dentro de la opinión pública, que relacionan los festivales con drogas, violencia, perdición y peligro; algo que deben tomar en cuenta los organizadores en sus estrategias de marketing. Como menciona el periodista $\mathrm{y}$ escritor estadounidense Michaelangelo Matos, los promotores aprenden a evitar situaciones "nadie quiere estar involucrado en un evento donde los jóvenes hagan cosas malas [por eso los promotores] no vendemos raves sino festivales de música o conciertos de DJ" (2015: p.354).

A pesar de estos incidentes, que pueden permear de una atmósfera sombría a los festivales, persisten con sus funciones míticas desde los niveles psicológico-moral y social-político; al poder lograr erigirse como rituales alternativos de ciertos grupos sociales, que escapan de las convenciones. Con tan solo revisar sus contenidos o asistir, es posible darse cuenta que promueven zambullirse en una dimensión externa a la realidad diaria, donde se puede desinhibir, establecer lazos, inquirir en la espiritualidad o solo gozar de la insólita experiencia.

Es una resonancia semántica la que permite identificar un momento cultural con otro, pero a la vez diferenciar su singularidad, es decir, es un evento comercial, pero también hay algo más dentro del mismo, donde las prácticas que emergen entre los asistentes hacen algo inédito: un nuevo nivel de realidad. En esta resonancia, la espiritualidad es vital, pues funge como el hilo conductor ante la experiencia, Gilbert Durand (2011) afirma al respecto: "Nuestro siglo entero, «el que cree en el cielo como el que no cree» parece anunciar el resurgimiento paraclético [...] sé que existe otro mundo. Está aquî"' (p. 347). Dentro de estos festivales hay una forma alternativa de entender lo que nos rodea, los valores, la identidad y el ser; la espiritualidad ya no se encuentra en forma de santos o dioses, sino de escenarios, $d j s$, baile y música.

\section{Conclusiones}

Para concluir habrá las ideas de algunos de los teóricos que han acompañado esta disertación. Rollo May (1992) considera que las narrativas míticas siguen vigentes en la actualidad, debido a que no se puede separar esta cualidad mitopoyética de la naturaleza humana. Es parte del ser la conformación de relatos que den coherencia al entorno, y el que se presenten en diversas modalidades hoy en día, solo obedece a las características de la sociedad moderna, la cual es heterogénea y compleja. No obstante, con una constante: la búsqueda de la identidad. Algo que en el caso de los festivales estudiados llevan a la práctica.

Es cierto que las afirmaciones de Mircea Eliade (2010) sobre la dimensión sagrada del mito es algo que no se preserva en la actualidad, hay una degradación de lo que en sociedades tradicionales concebían como narrativa mítica, pero aún así, los mitos "modernos" revelan un fondo existencial sobre la vida humana. Puede ser que se muevan en lo profano, empero hay reflejo de una gran pérdida de valores y un empobrecimiento de las relaciones interpersonales, algo que Tomorrowland, EDC y Burning Man buscan combatir a partir de sus discursos e infraestructura. Se tiene presente que son eventos comerciales, que se insertan en la lógica de la sociedad de mercado, pero aun así ¿acaso no pueden existir en su interior la aparición de prácticas significativas que surgen al margen de lo preestablecido y permiten que los involucrados accedan a otros niveles de sentido?

Lluis Duch (2008) apoya el previo planteamiento al resaltar la importancia de las historias en la vida, ellas son las responsables de dar un rumbo, y en esos relatos nunca 
hay una sola interpretación, pues no hay un discurso cien por ciento transparente; cada persona hace una apropiación de ese contenido. Cada quien es agente activo de su entorno.

Respecto a la categoría central que son los cauces míticos y la metodología que es la hermenéutica analógica; es prioritario señalar que pueden utilizarse como una metodología para diferentes fenómenos sociales y/o productos de la industria cultural o incluso de otras disciplinas. Lo anterior debido a que al permitir la detección a través de similitudes y diferencias de cómo se mueve una narrativa mítica en el imaginario colectivo al interior de una época o cultura específica, puede trasladarse este modelo a diferentes contenidos o situaciones. Por ejemplo, un videojuego, un proceso electoral, una serie, una película, una obra de arte, una red social digital, una ceremonia religiosa, entre otros, pues un cauce mítico se concibe como una tendencia que fluctúa dependiendo de las necesidades en el tiempo y el espacio en donde se manifiesta. En el caso analizado sobre Dioniso, su presencia en los festivales es constante, se observa un neopaganismo dentro de ellos: el éxtasis, la ruptura del orden y el derrochamiento de emociones son constantes.

Hay que puntualizar el que estos festivales no tienen la clandestinidad que manejaban los raves o que tuvieron otros eventos de música y baile como los sound system en Jamaica. Como ya mencionó, se insertan dentro del aparato comercial, empero a ser productos mercantiles, conservan cierta esencia que permite observarlos como vetas del mito a Dioniso. Fomentan una cultura participativa, la libertad de expresión y la catarsis ante la rutina cotidiana, buscan que sea soportable lo insoportable. Como reza el «manifiesto raver» de autoría desconocida:

Buscamos el mostrarnos a nosotros mismos de la opresión de un futuro incierto el cual ustedes no han podido estabilizar y asegurar para nosotros y para las futuras generaciones. Buscamos liberarnos de nuestras inhibiciones [...] unir nuestras manos y levantarlas al compartir este gozo incontrolable que sentimos al crear esta burbuja mágica que puede, por una noche, protegernos de los horrores, atrocidades y la contaminación de nuestro mundo [... ] La música nunca se detendrá, el latido de nuestro corazón nunca desvanecerá. La fiesta jamás terminará.

(Lenin xd 3.0, 2009)

El cauce mítico dionisiaco no se detiene solo en los festivales mencionados, se puede encontrar en numerosas manifestaciones culturales, lo cual provoca que la cuenca semántica de dicho mito se extienda en diversas vetas. Hoy más que nunca se está rompiendo la normalidad sistémica y se pueden observar diversos esfuerzos que alzan un mensaje de diversidad, apertura y nuevas vías para alcanzar la espiritualidad y comprensión del mundo:

Es esto lo que conviene pensar: la mutación de una existencia dominada por el materialismo moderno, es decir ya anticuada, hacia otra manera de estar-juntos en donde lo inmaterial vuelve a encontrar fuerza y vigor. Se trata de valores inmateriales que están en plena vigencia en la vida política, social y económica. Y no carece de interés el que las jóvenes generaciones sean las protagonistas de esta nueva mirada a la naturaleza y a la sociedad. (Maffesoli, 2012: 218)

Amador (2004) con sus dimensiones sobre el mito puntualiza los alcances social-político y psicológico y moral que puede llegar a tener, y en el caso de las narrativas que se manejan en estos festivales, es vital analizarlas. Tal aseveración debido a que son reflejo de lo que caracteriza y aqueja a la sociedad hoy en día, donde de forma continua hay una transvalorización de las instituciones y discursos. Así pues, lo que pasa en estos eventos ocurre del mismo modo: va más allá de música, baile, drogas y excesos, son alternativas a transformar la existencia, respuestas ante la tragedia y cansancio continuo que aqueja. Esta «visión dionisiaca» del mundo es una vía de comprensión fuera de lo que el sistema como tal propone, que inserta en otros cuestionamientos y necesidades.

La importancia de este estudio es otorgar una aproximación y legitimación a estas manifestaciones que de pronto pueden ser desdeñadas por las investigaciones formales, pero que en realidad son formas de expresión válidas que dan testimonio de cómo el ser humano tiene una necesidad ontológica de espiritualidad. Estos festivales otorgan una vía para acceder a ella, tal vez no sea la más tradicional, pero 
tampoco puede negarse su fuerza integradora. Son válvulas de escape ante el control cotidiano, una oportunidad de dejarse llevar y romper con lo disciplinario, de tener una experiencia distinta hacia otro thelos a través de su cauce mítico.

\section{Referencias}

Amador Bech, Julio (2004) Las raíces mitológicas del imaginario político. México. UNAM.

Arbiser, Samuel (2017) “Acerca de la función mitopoyética de la mente”. En: Revista Psicoanálisis. Vol. XXIX. No.1-2017. Buenos Aires. Pp. 125-143

Barelli, María Cecilia (2017) "Transformaciones de "lo dionisíaco": un análisis sobre el giro de Nietzsche en Humano, demasiado humano" Diánoia, vol. LXII, núm. 78, mayo, 2017. UNAM. pp. 47-73

Beuchot, Mauricio (2018) Teoría estética. La resurrección del arte. México. Ed. Orfila.

Bones, Frankie, citado por Sterling, Scott (2016) "Frankie Bones on the Origins of PLUR" Revista Digital Insomniac Magazine. 7 Enero, 2016. Disponible: https: //www.insomniac.com/magazine/frankie-bones-on-th e-origins-of-plur/

Burning Man (2019) "The event" Sitio Web Oficial. Disponible en: https://burningman.org/event/brc/

Cassirer, Ernst (2009) Antropología filosófica. México. Fondo de Cultura Económica.

Chevalier, Jean (1986) Diccionario de los símbolos. Barcelona. Ed. Herder.

Duch Lluís, et.al. (2008) Lluís Duch, antropología simbólica y corporeidad cotidiana. México. UNAM-CRIM.

Durand, Gilbert (1981) Las estructuras antropológicas de lo imaginario. Madrid. Taurus.

Durand, Gilbert (2011) La crisis espiritual en occidente. España. Siruela.

Durand, Gilbert (2012) “La mitocrítica paso a paso” En: Acta sociológica. No. 57. Enero-Abril 2012. pp. 105-118.

EDC México (2019) “En lo que creemos” Sitio Web Oficial. Disponible en: https://mexico.electricdaisycarnival.com /what-we-believe/

EDC Mx (2019) "El mundo de EDC" Sitio Web Oficial. Disponible en: https://mexico.electricdaisycarnival .com/experience/the-world-of-edc/

Eliade, Mircea (2010) Mito y realidad. Barcelona. Editorial Labor.

Fernández Vega, Pedro A. (2018) Bacanales. El mito, el sexo y la caza de brujas. España. Siglo XXI.

Gadamer, Hans Georg (1997) Mito y razón. España. Paidós.

Lenin xd 3.0 (2009) "Manifiesto raver" Blogspot. Disponible en: http://leninxd.blogspot.com/2009/04/manifiesto-ra ver.html
Maffesoli, Michel (2012) "La fuerza de la debilidad dionisiaca” En: Revista Colombiana de Antropología, vol. 48, núm. 2, julio-diciembre, 2012, pp. 211-218

Matos Michaelangelo (2015) The underground is massive. USA. Dey Street Books.

May, Rollo (1992) La necesidad del mito. España. Paidós.

Ong, Walter (2016) Oralidad y escritura: tecnologías de la palabra. México. FCE.

Tomorrowland (2019) “Welcome”. Sitio Web Oficial. Disponible en: https://www.tomorrowland.com/en/ festival/welcome

Wilkinson, Philip (2009) Mitos y Leyendas. Guía Ilustrada de su origen y significado. DK. China.

YouTube (2012) "Q-dance at EDC Las Vegas I Official Q-dance Aftermovie”. Channel Q-Dance. 13 Julio 2012. Disponible en: https://youtu.be/ty_3egPmXZE. 21-35.

YouTube (2016) "EDC Las Vegas 2016 Official Trailer". Channel Insomniac Events. 28 Abril 2016. Disponible en: https://youtu.be/Zo47D-ZeMmI.

YouTube (2016) "Tomorrowland 2016 I Introduction Trailer The Elixir of Life”. Channel Tomorrowland. 5 Julio 2016. Disponible en: https://youtu.be/pliBB2la3n8

YouTube (2017) “EDC Las Vegas 2017 Official Trailer”. Channel Insomniac Events. 6 Abril 2017. Disponible en: https://youtu.be/LzuHNfzdx4I 